\title{
MERGERS AND ACQUISITIONS AS A SOURCE OF BUSINESS RESTRUCTURING
}

\author{
Irina V. Onyusheva \\ Natasya E. Gulla
}

Stamford International University, Bangkok, Thailand

This paper investigates the sophisticated essence of mergers and acquisitions (M\&A) as a source of business restructuring in the industrial world, including manufacturing and service industries. It presents the picture of assumed purposes and conditions for such M\&As and the outright benefits of $M \& A s$ for businesses. The authors consider the characteristics, trends as well as success cases in the M\&As field. Several research methodologies are implemented to analyze the business environment and identify the goals and the strategies to be developed for the purposes of $M \& A s$ on the basis of comparative analysis of the successful real-life examples of $M \& A s$.

Keywords: mergers and acquisitions (M\&A); business restructuring; economic growth

\section{Introduction}

Merger and acquisitions (M\&A) are an integral part of corporate economies and are often used as the fastest ways to provide return to investors and shareholders. The return on investment (ROI) is the key element of any business. The shareholders of businesses have their expectations set and are looking for a certain rate of return (Junni \& Teerikangas, 2019). To satisfy investors and shareholders' greed, the company must grow continuously and bring return to investors and shareholders.

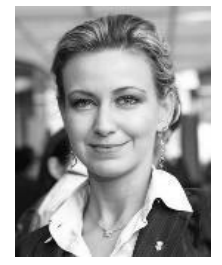

STAMFORD UNIVERSITY unleash Your Potential

\section{Irina V. Onyusheva}

PhD, Prof. Stamford International University, Bangkok, Thailand.

Research interests: strategic management; ensuring economic competitiveness on microand macro- levels; human capital development; HR management; knowledge economy; project management; management in education.

E-mail: dr.irina.onyusheva@gmail.com

\section{Natasya E. Gulla}

MBA, Stamford International University, Bangkok, Thailand

Research interests: international business management, strategic management; change management.

E-mail: natasya.gulla@gmail.com 
In the recent years we have witnessed a dramatic increase in the number of M\&As and their drastic increase in revenue and profitability. To name a few, Amazons, Apple, Facebook, Google etc. Their seasoned executives are always looking for an opportunity to expand their revenue growth and please the shareholders. This is a more common business practice in the US rather than in any other countries. Although M\&As happen worldwide, the major share belongs to the US-based companies (Sherman et al., 2006). This is one of the reasons why corporate executives are able to earn substantial salaries in comparison with average workers.

\section{The essence and features of $M \& A$}

In general, the growth of companies comes in two forms. These are organic growth and inorganic growth (PricewaterhouseCoopers). Organic is an internal growth in which investments come inward and help the business grow. Inorganic growth is external, it is formed through alliances or partnerships, joint ventures, and M\&As. Organic growth is often slow. This is due to the existence of multiple elements within the company which must grow in parallel to supplement the total growth of business.

In large organizations, such parallel growth across all divisions is often tedious and takes a lot of time. On the other hand, M\&As are a much faster form of growth since an M\&A assumes buying out already established entities. However, M\&A has its own strengths and weaknesses. It is not that easy as it sounds.

Within capitalistic economic structures, growth and ROI are the uncompromised goals of companies. Meeting the ROI goal requires revenue and profitability which, in its turn, requires business growth.

Revenue and profits are not easy targets. Tremendous amount of work is required for generation and increase of revenues and profitability. In simple terms, businesses must grow to achieve returns. In the case of organic growth, mentioned above, business growth has many factors integrated, and all these factors rest on the one main component - the time factor. This means the return on organic growth is time dependent, and in some cases it might take a while to see some progress. However, greedy investors and shareholders often disregard this time factor and demand for an immediate ROI.

This is where the conflict arises between top management and shareholders, and thus, the alternative growth options arise. M\&A opportunity is one of these options. With the proper strategy, M\&A can deliver results in a much shorter period of time (Creighton, 2013).

M\&As can take place between companies not only within the same country but also cross border. Within the same country an M\&A may be easier since the buyer faces the same diversity and culture of employees, same government regulations in terms of labor, environmental and antitrust law, etc. At the same time, cross-border M\&As have many challenges such as diversity of the workforce, differences in culture and traditions, new labor and environmental rules, new regulations in part of corporate governance. In a nutshell, there is no universal standard, and every country varies in the abovementioned factors. Therefore, M\&As carried our cross border present much larger challenges than M\&As within the same country.

Governments all around the world have put in place specific legislations to balance the relationship between corporations and consumers. These laws, one the one hand, provide protection to consumers and also help corporations to succeed (Roberts et al., 2003). The 


\section{THE INFLUENCE OF MANAGEMENT POWER}

level of consumer protection and corporate leverages varies across different countries. Some countries may be more pro-business rather than pro-consumer, and vice versa.

Therefore, M\&As will never be subject to the same rules and regulations, and potential buyers should analyze the impact of these rules and regulations against their strategy of growth before engaging in an actual M\&A. Conducting M\&A always has a range of preconditions that will have to be met to be successful.

Fig. 1 shows the most typical flow of M\&A and the relevant restructuring.

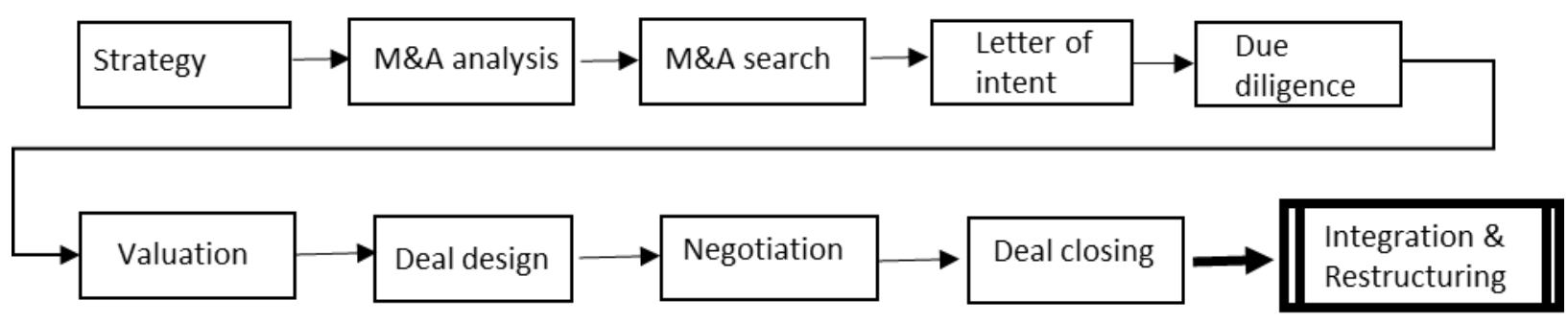

Figure 1 - Typical M\&A Flow

(Source: Roberts et al., 2003)

Before contemplating on an M\&A, the company should look inward to identify their problems hindering own growth and/or potential opportunities to grow faster. They should conduct SWOT analysis to identify the gap they need to fill in with the help of an M\&A. Then they should weigh-in between organic growth and M\&A. The key research result will point towards the right strategy of organic growth or M\&A. If the research result is more in favor of an M\&A, the company should begin to develop its M\&A strategy.

Strategy: The strategy is the key and the fundamental factor for any M\&A. The strategy reflects the purpose of an M\&A. It should address the following questions.

What is our growth plan and target?

What is hindering our growth?

What sort of research analysis should be conducted to identify strengths, weaknesses, and opportunities?

What is the gap that needs to be filled to increase growth?

What kind of M\&A will complement these gaps?

The strategy should also include the buyer's perspective and the seller's perspective. Therefore, the search for M\&A can be clearly defined from its very start.

Buyers' perspective: The buyer has several reasons to buy other businesses. Some of such reasons maybe as follows:

Buyer has the capital and wants to expand business growth.

Buyer is under pressure because shareholders demand to increase ROI.

Buyer wants to eliminate potential competition, already present or potential.

Buyer has excess capital and wants to add a complementary business to the current one.

Buyers' existing business is at the declining stage, thus, buyer wants to get hold of a new technology and/or a product.

Buyer wants to enter new markets, in other regions or countries. 
Buyer wants to extend their distribution channels through acquisition of a business in the same category.

Sellers's perspective: The seller has several reasons to sell their business. Some of these reasons could be as follows:

The company needs cash infusion to go to the next development level.

The company is quickly losing its market share due to the lack of innovation.

The product or technology is in decline or is coming to the end of its life cycle.

The investment is digested and the capital needs to be redirected to other areas.

The company is engaged in disputes, internally or externally.

M\&A Search: In today's world, it is relatively easy to identify the companies for purchasing. There is a great deal of publicly available information in the Internet. However, knowing the actual status of a company and approaching this company is trickier. One way is to approach through dedicated agents who specialize in M\&A deals (PricewaterhouseCoopers).

Letter Of Intent (LOI) and Memorandum of Understanding (MOU): The letter of intent (LOI) is the first stage of an M\&A. The buyer indicates their intention to purchase the seller's business. The seller will then decide and prepare necessary planning. Although LOI is not a fully legally binding document, it is regarded as worthy of consideration.

MOU allows the seller to give all relevant documents, especially financial information related to the company for the buyer to review and decide.

Due Diligence: This is one of the most important parts of any M\&A. The buyer should scrutinize all the information, documentation, and other relevant matters as to the company to be purchased. The buyer will also confirm all the information gathered as to its authenticity. (Roberts et al., 2003).

Valuation: Company's valuation is a key part since the offer is based on the net present value (NPV) of the company. The buyer should come up with a convincing argument about the offer based on the gathered financial history and the current marketing position of the seller. The buyer should demonstrate the future prospects of the seller;s business and from that prediction draw NPV. This is usually the bargaining point of the sales and purchase (Roberts et al., 2003).

Deal design: The buyer should design a deal that makes the seller gain reasonable value from selling the business. Otherwise, the seller may not sell the business at all. However, designing a deal may vary in a great deal of details. The NPV is a crucial part of the deal design. Beyond the financial numbers of direct cost, there are also indirect costs involved such as employees' benefits and other related matters, debt payments, for example. Therefore, design of the deal must be comprehensive and convincing for the seller (Sherman \& Hart, 2006).

Purchase Agreement: Once the deal is agreed by both parties, it can be legally drafted according to the law of the land, and the purchasing agreement can be completed. Depending 


\section{THE INFLUENCE OF MANAGEMENT POWER}

on the nature of M\&A, some of them may need to be approved by some legislative bodies of the buyer's or seller's country or in some cases by both countries' governments (Sherman, 2018). If the companies' businesses have any relation to the national security issues, the M\&A usually requires the relevant government's approval.

Authority Approval: In many countries, the government bodies try to protect consumers from the corporate cartels. M\&A deals can pave the way for monopolizing the market, then consumers will lose their bargaining power provided to them under fair competition conditions. M\&As can indirectly lead to the fixing of prices, thus, consumers, again, lose their bargaining power. For this very reason, many countries implement the antitrust laws to ensure consumers do not get cornered by the corporate cartels. Therefore, some of the M\&As may need additional approval (Sherman et al., 2006).

Closing the deal: Once both parties agree with the purchasing agreement and have collected all necessary authorization documents from the respected authorities, the deal may be closed, and M\&A can be completed, at least on paper. However, the real M\&A begins only when the agreement is signed (Sherman et al., 2006).

Integration, Restructuring and Consolidation: The core purpose of M\&As is to strengthen the company in a number of aspects, primarily so that its growth and sustainability can be expanded in both short and long terms. Therefore, M\&A on paper alone will not bring the desired outcomes (Sherman et al., 2006). Companies must realign their entire operations and therefore undergo financial, operational, and organizational restructuring and consolidate their positions to face the stage of new growth. As a result of such an realignment, the following processes will take place:

Robust positioning in the industry and the market;

Rapid revenue growth;

Market share getting larger or niche position getting wider;

Opportunity to break the market entry barriers imposed by local competition;

Stronger management team and an updated pool of skills set.

Brand retention: In the process of an M\&A the buying and the selling companies will undergo major changes. Usually, the buyer will maintain some level of identity and keep the management team. One special case is when an M\&As takes place between branded companies to increase and consolidate their market shares and place barriers to competition from other players.

In this case both companies try to maintain their names at the market.

One such example of Daimler Chrysler.

When Daimler Benz merged with the Chrysler corporation in the US, they renamed the new entity as Daimler Chrysler because both names are very popular and reputable.

Mergers and acquisitions have already played a variety of roles in the corporate history, ranging from the "Greed is good" corporate riders buying companies in hostile takeovers and breaking them apart back in the 1980s to today's trend of using M\&A for strategic growth and to foster industrial consolidation.

During the 1980s roughly half of the companies were restructured and 80,000 were acquired or merged, over 17000 sought bankruptcy protection to continue operations 
(Sherman, 2018). This was the beginning of a new era. During those 1980s, the purpose of many M\&As used to be catering to the "Greed is good "strategy, thus, very aggressive tactics were used while gaining control over the targets. In the 1990s the situation reshaped, and so did the purposes of M\&As.

During the 1990s with their dynamic changes, the companies pursued different approaches such as evolving through upsizing and growth, downsizing, rollups, and consolidation. The companies focused more on the operational synergies, strategic alliances, expanding customer base and market share and pursuing new technologies (Sherman, 2018).

According to our literature review, the M\&A culture initially emerged in the US and now continue to grow and expand. During the time period of active growth in Japanese economy, Japanese companies got engaged in M\&As as well. But, for Japanese companies it is more about acquisition rather than about the merger. The driving force behind Japanese purchasing spree was excess capital. At the same time, Japanese companies may have a lot of reservations concerning the phenomenon of a merger due to the historically closed society in Japan, language barriers and also Japanese reservations in relation to diversity.

According to the Mergermarket report, back in 2016 the total value of M\&As that took place was 3.25 trln USD. This includes a wide range of industries worldwide and the total of 17,769 deals completed. The trend continued in 2017 and then started to cool off under Trump's administration. The COVID situation has further deteriorated the opportunities for M\&As.

The first quarter of 2021 is significantly lower as compared to 2016 but still shed some light on the ongoing M\&A deals. "Though the deal value jumped 17.4 per cent to USD 25.3 billion across 97 deals, over USD 21.6 billion across 122 deals, which means the deal volume is down 20.5 percent during the same period over the same period last year".

\section{The Research Problem, Goals, and Objectives}

\section{Goals and Objectives}

As mentioned above, M\&As are often used for faster growth and higher return to investors and shareholders but they are not limited to these two purposes. M\&A's are also used for eliminating rivalries or merging with competition against a common enemy. An interesting example in this regard are long-time rivalries QVC and Home Shopping Network that merged back in 2017 trying to stay competitive against Amazon (Creighton, 2013). Despite the initial purposes, the end goal is still the same - to increase growth and faster growth. Therefore, the goal and objectives should be clearly defined in advance.

\section{Research Problem and Analysis}

When it comes to M\&As, the problem arises what sort of M\&A the company wants to pursue. What are the current problems of the company and where the company stands at the market? There are no standard procedures or theories to follow when it comes to M\&As. M\&As are always purpose-based, and this purpose should be clearly identified. The failure to identify the purposes at the beginning will lead to a wrong strategy and thereby wrong outcomes from the M\&A.

The purpose of the M\&A is to complement the current business and not to corrode it.

Historically, not all M\&As were actually successful. The question arises in relation to all these failed M\&As, "if they did their homework prior to signing up the deals". It is 


\section{THE INFLUENCE OF MANAGEMENT POWER}

imperative for the buyer to understand and identify their true purpose behind an M\&A and which seller can fit into the purposes.

Therefore, the buyer can come up with the right strategy and the right match to these needs. Therefore, the first step the management must come up with is strategic planning. There are a number of analytical tools available; however, none of these tools can offer a strategy. But they provide insights and serve as inventory, for example, firm's SWOT.

\section{The SWOT Analysis}

This is an excellent tool to identify the true needs behind M\&A. SWOT analysis will also help to plan the right strategy for an M\&A (Bruner, 2004). It includes several relatively easy steps as follows.

Assessing the firm's competitive position at the market.

Determining the firm's position in its competitive environment along with its internal resources and capabilities. The assessment aims to profile the industry and the firm's position in it under several dimensions:

Structure of the industry and the intensity of rivalry in it;

Sources of turbulence that may trigger shifts in the industry's structure;

Dimensions of relative strengths and weaknesses among the players within the industry;

Propensity of individual players to take action, exploit change forces and alter the industry's structure;

Drivers behind competitive strengths and weaknesses in the industry;

Outlook for profitability in the industry.

The result of such a research analysis would also give an answer as to an M\&A strategy, namely, what's the best option - merger or acquisition. The differences between mergers and acquisitions are stated below.

Merger: A combination of two or more companies in which the assets and liabilities of the selling firm(s) are absorbed by the buying firm. Although the buying firm may be $\phi$ considerably different organization after the merger, it retains its original identity (Sherman, 2018).

Acquisition: Purchasing assets such as a plant, a division or even the entire company (Sherman, 2018).

\section{PESTEL Analysis}

PESTEL contains six elements or factors. This type of analysis can also contribute to the M\&A process. These six factors in PESTEL in relation to M\&As are can be described as follows (Andriuskevicius \& Streimikiene, 2021; Singh, n.d.):

Political factors are triggered by the relations with foreign governments, stability in politics, and/or government intervention in the economy. Political factors may affect mergers and acquisitions as some companies will not take the risk to enter a country that has an unfavorable political environment or a country where governmental intervention in business activities is more than desired.

Political factors have a significant role in M\&As as they influence potential investors psychologically and make them wisely choose the economy, which is most politically stable and favoring the interests of investors in pre-merger and post-merger situations. 
Economic factors are directly connected to the financial position in a host country, economic stability, financing rate, and the market proposition. Spending psychology of the local people is also part of this group. Economic factors play a significant role for the companies in the M\&A process since they partially predetermine whether the potential restructuring will be successful or not. The volume of cross-border M\&A activities may also depend on the financial and other policies in a country.

Social factors concern cultural similarities and differences of people, including religion, race, etc. These factors will become visible once the restructuring is done and the operational process continues.

These are the factors that some businesses fail to consider or notice at the early stages of an M\&A process, as the primary focus is on the business. Social factors or cultural issues may also effect the pre-merger decision-making, negotiations and deal structuring as well as the post-merger integration.

Technological factors are important tools that can improve a company's operations and functions. Over the past decades, developments in technology have greatly improved the state of economy as such. The impacts of technology on business operations started from the transition of manual labor to machine equipment. Later on, technology has also impacted the marketing strategies. There are two roles of technology in the M\&A process - the Catalyst and the Enabler.

\section{The Catalyst}

Technological transformations in the form of digital technologies, cloud, analytics, the Internet of things (IoT) and artificial intelligence have already introduced new business models and changed the way of communications between companies. M\&A opens the door to such game-changing transformations. Forward-thinking communications, media, and hightech companies are acquiring the companies with technological expertise so that they can develop new offerings, redefine industry boundaries and drive growth.

\section{The Enabler}

Technology is the key enabler leading to synergies and creating challenges for the newcomers at the same time. M\&A deals are able to improve the quality of the resulting IT environment.

Environmental factors are related to climate change, weather conditions, renewable and non-renewable energy, types of goods available, and the environmental laws that must be followed in the course of business activity. Environmental factors play a significant role in the M\&A deals.

Companies need to consider climate and weather change as the uncontrollable factors that have direct impact on business operations, namely, profitability, business management process, cross-border acquisitions performance and so on.

Legal factors may decide the fate of the business which has been restructured as a new entity. Legal factors require due diligence on the parties involved in the transaction. Here belong antitrust laws, taxation policies, corporate social responsibility, intellectual property rights law, consumer protection laws, etc.

Legal factors have a significant effect on M\&A transactions. Disregarding these factors may lead to complex legal problems and extra fees in the future. Companies should do due 


\section{THE INFLUENCE OF MANAGEMENT POWER}

diligence before the M\&A deals. This can give a better idea whether the objective behind the merger/acquisition may be met or not.

\section{M\&As: Success stories}

There are numerous companies that have succeeded in their M\&As. Some of these companies are listed below and are ideal examples as part of our research results.

A. Microsoft bought LinkedIn for $\$ 26.2$ billion. In 2016, Microsoft acquired LinkedIn for $\$ 196$ per share in the all-cash transaction valued at $\$ 26.2$ billion in total, inclusive of LinkedIn's net cash. Under this acquisition, LinkedIn retained its distinct brand, culture, and independence. LinkedIn is the world's largest and most valuable professional network and it continues building a strong and growing business (Microsoft News Center, 2016).

With this acquisition, Microsoft wants to bring together the world's leading professional cloud with the world's leading professional network. LinkedIn provides the network for people to find jobs, build skills, sell, market, and get work done. Professional information in the LinkedIn's public network may be combined with the information in Office 365 and Dynamics.

This brings in new experiences, such as LinkedIn newsfeed that serves up articles based on the project you are working on and Office suggesting an expert to connect with via LinkedIn to help with a task you are trying to complete (Tweedie, 2016). In this case, Microsoft and LinkedIn have applied product extension mergers since the companies have very different products but are related to the same market (Hayes, 2021).

B. Apple buys Dr. Dre's BEAT music for \$3 billion. In 2016, Apple announced the acquisition of Beats Electronics for $\$ 3$ billion. Beats Electronics is a headphone and music streaming company. In the music streaming industry, Apple already had iTunes and a catalog of digital music to purchase, but the iPod generation is coming to an end. Making sure that the on-demand subscription service keeps up with the industry's pivot, Apple decided to buy Beats Electronic rather than build its own product.

Tim Cook then said that music is such an important part of our lives and holds a special place within our heart. This is part of the reason why Apple kept investing in music, bringing together extraordinary teams so that people can continue to create the most innovative music products and services in the world. On the streaming side alone, the investment has paid off. Apple has cemented itself as a key player in how people are now listening to music (Steele, 2019).

After the acquisition, Beats Electronics released new headphones as part of the iPhone 7 campaign. Beats announced that it had three new headphone options in the works. All three would feature the W1 chip that powered Apple's own wireless AirPods.

The Power beats 3, Beats Solo3 Wireless and the eventually delayed Beats-X would pack in quick-pairing features, improved battery life, and Fast Fuel rapid charging. Apple had benefited from Beats' streaming service and now Beats headphones were benefiting from Apple's engineering smarts. The company followed up a year later with the fourth model that leveraged the power of the W1 chip: the noise canceling Studio3 Wireless (Steele, 2019). In this case, Apple and Beats Electronics applied product extension mergers since the companies have different products that are closely related though (Hayes, 2021).

C. Amazon buys Whole Foods for $\$ 13.4$ billion. In June 2017, Amazon announced the acquisition of Whole Foods Market, Inc. with the total transaction of \$13.7 billion. Whole Foods Market continues to operate its stores under their brand and the business structure and 
location remain the same, in Austin, Texas (Sangwan, 2017). This acquisition shows Amazon has the interest to expand its business into the grocery. Amazon wants to turn into a more frequent shopping habit by becoming a big player in the food and beverage industries. The acquisition of Whole Foods Market has been a big decision for Amazon after almost a decade of selling groceries online. This can provide fresh ingredients such as fruits, vegetables, and meats directly to customers (Wingfield \& de la Merced, 2017).

After that, Amazon introduced their own delivery service called Amazon Fresh with its "click and collect" model that lets the customers buy groceries online and pick them up in person. The supermarket business, like many other parts of retail, has been hit hard by increased competition from Amazon itself as well as Walmart (La Monica \& Isidore, 2017). In this case, the type of merger has been a congeneric merger since both companies have the same customer base buying groceries, but Amazon provides the convenience of buying online and Whole Foods Market customers need to spend some time inside the store to buy their groceries (Hayes, 2021). This acquisition provides customers with both of these experiences mentioned above. Now a customer can choose and buy groceries online and the store will pack the order for them. After that the customer can come to the store and pick up their order. With this service, the customer does not need to spend time in the store and can get fresh ingredients as soon as possible.

D. 7-11 acquires Sunoco chain gas station for $\$ 3.3$ billion. $7-11$ is a snack and convenience store chain. In 2017 it announced the acquisition of more than 1,100 convenience locations from Sunoco. This acquisition meant to escalate the company's expansion plans in the USA. Sunoco currently operates in tandem with gas stations across 18 states. This deal will boost the total number of 7-11 to 9,815 stores in the US and Canada (McCoy, 2017). The acquisition also comes with an agreement that 7-11 will buy gasoline for operations from Sunoco during the next 15 years (Kezar, 2018).

Sunoco has already distributed gasoline to 6,800 stores of 7-11 in the US. The deal is an acquisition agreement and does not involve any assumption of interest-bearing debt, the company said. In this case, the type of the merger is conglomeration: 7-11 and Sunoco do not have similarities in their businesses (Hayes, 2021). The acquisitions helped 7-11 to expand its presence at the market of convenience stores in the US. This is also an applied vertical merger since Sunoco becomes the supplier of the 7-11 operational gasoline.

E. Burger King buys Popeyes for $\$ 1.8$ billion. In 2017, the parent of Burger King and the Tim Hortons doughnut $\&$ coffee chain announced they are acquiring Popeyes Louisiana Kitchen for $\$ 1.8$ billion (La Monica, 2017).

This acquisition helped with developing the brand at an increasing pace in the US and foreign markets. To the total of 15,000 Burger King locations and 4,500 Tim Hortons, the Popeyes acquisition will add another 2,600 outlets to the portfolio (Filloon, 2017). This acquisition presented major opportunities to Popeyes in terms of expanding the business and reaching to the customers of its key competitor, KFC. After this acquisition, Popeyes can manage its operation independently and keeps the brand (Bomey, 2017).

This case is a horizontal merger since both companies are working in the same business industry as fast-food chains (Hayes, 2021). Such a type of acquisitions helps expanding the business and reducing direct competition. 


\section{THE INFLUENCE OF MANAGEMENT POWER}

\section{Conclusion}

The M\&A deals became popular back in the 1980s and continue to be widely spread to date. Most of the M\&As are still taking place in the US, resulting in billions and trillions of US dollars in the deals.

The capitalistic economy as such caters such M\&As. M\&As are much less popular in other countries of the world though. The trend of M\&As scales up changes in Chinese economy, shifting it more into capitalism. China has already allocated over a trillion of dollars into its M\&A deals.

The cases considered above show that buyers may have several purposes for the M\&As. The purposes vary from simple growth to eliminating rivalry, challenging market dominance, and expanding distribution channels. Under competition at the global markets, M\&As are often useful for further expansion. For example, MBE Worldwide bought its rival, Franchisor Post Net to establish its distribution network in over 30 countries.

M\&A can be successful provided the buyer company has a clear strategy and understands all the potential pitfalls of an M\&A deal. On paper, M\&A may look really simple, however, the challenges start when the actual integration starts.

Depending on whether an M\&A is within a country or is a cross-border one, integration may become a real challenge. Cross-border M\&As failed a lot during the 1980s, primarily due to the lack of understanding of the cultural differences.

However, over time, the right expertise has been developed and presently various skills are available to help in the M\&A process. As a result, the companies mentioned above succeeded in their M\&As.

Today M\&A is a vital part of economic growth, and is also one of the top revenue generators.

\section{References}

Andriuskevicius, K. \& Streimikiene, D. (2021). Developments and Trends of Mergers and Acquisitions in the. Energies, 1-14.

Bomey, N. (2017). Burger King owner to buy Popeyes fried chicken for \$1.8B. Available at: https://www.usatoday.com/story/money/2017/02/21/burger-king-popeyes-timhortons/98189186.

Bruner, R. F. (2004). Applied Mergers and Acquisitions. New Jersey: John Wiley \& Sons, Inc.

Creighton, K. (2013). Introduction to Mergers and Acquisitions. Bookboon.com.

Filloon, W. (2017). Burger King Buys Popeyes for $\$ 1.8$ Billion in Fast-Food Mega-Merger. Available at: https://www.eater.com/2017/2/21/14672830/burger-king-popeyes-merger-timhortons.

Hayes, A. (2021). Guide to Mergers and Acquisitions. Available at: https://www.investopedia.com/terms/m/mergersandacquisitions.asp.

Junni, P. \& Teerikangas, S. (2019). Merger and Acquisitions. Oxford Research Encyclopedia of Business and Management, 1-35. 
Kezar, K. (2018). 7-Eleven completes $\$ 3.3 B$ purchase after agreeing to divest stores. Available at: https://www.bizjournals.com/dallas/news/2018/01/25/7-eleven-completes-3-3b-purchase-afteragreeing-to.html.

La Monica, P. R. (2017). Whopper of a deal: Burger King owner buys Popeyes. Available at:: https://money.cnn.com/2017/02/21/investing/restaurant-brands-burger-king-popeyesacquisition/index.html\#: :text=Restaurant $\% 20 \mathrm{Brands} \% 2 \mathrm{C} \% 20$ the $\% 20$ parent $\% 20$ of, where $\% 20$ the $\% 20$ stock $\% 20$ closed\%20Friday.

La Monica, P. R. \& Isidore, C. (2017). Amazon is buying Whole Foods for $\$ 13.7$ billion. Available at: https://money.cnn.com/2017/06/16/investing/amazon-buying-whole-foods/index.html.

Microsoft News Center (2016). Microsoft to acquire LinkedIn. Available at: https://news.microsoft.com/2016/06/13/microsoft-to-acquire-linkedin/

Pricewaterhouse Coopers. (n.d.). Mergers and Acquisitions.

Roberts, A., Wallace, W. \& Moles, P. (2003). Mergers and Acquisitions. Britain: Edinburgh Business School.

Sangwan, P. (2017). Amazon Acquires Whole Food. Available at: https://mnacritique.mergersindia.com/amazon-whole-foods-acquisitions.

Sherman, A. J. (2018). Mergers and Acquisitions from A to Z Fourth Edition. New York: American Management Association.

Sherman, A. J. \& Hart, M. A. (2006). Mergers and Acquisitions from A to Z Second Edition. New York: American Management Association.

Singh, A. R. (n.d.). Pestel Analysis in Merger and Acquisitions. Available at: https://legalwriting.eu/pestel-analysis-in-mergers-and-acquisitions.

Steele, B. (2019). Apple's $\$ 3$ billion purchase of Beats has already paid off. Available at: https://www.engadget.com/2019-05-28-apple-beats-five-years-later.html.

Tweedie, S. (2016). Microsoft Buys LinkedIn for $\$ 26.2$ Billion. Available at: https://www.businessinsider.com/microsoft-buys-linkedin-2016-6.

Wingfield, N., \& de la Merced, M. J. (2017). Amazon to Buy Whole Foods for $\$ 13.4$ Billion. Available at: https://www.nytimes.com/2017/06/16/business/dealbook/amazon-wholefoods.html.

Paper submitted

Paper accepted for publishing

Paper published online
11 June 2020

26 August 2021

30 September 2021 